\title{
Gestão da Conta Vinculada, Teoria do Stakeholder e Performance Prism Aplicados aos Contratos de Terceirização Estudo de Caso na Universidade Federal de Goiás
}

\author{
http://dx.doi.org/10.21527/2237-6453.2019.49.348-366
}

Recebido em: 1 인/2018

Aceito em: 27/5/2019

Eliseu Vieira Machado Júnior ${ }^{1}$, Bruno Lobão Lopes²

\begin{abstract}
RESUMO
A obrigatoriedade da conta vinculada nos contratos de terceirização inseriu a Administração Pública Federal numa arena em que se apresentam diversos interesses: Direitos dos trabalhadores terceirizados, das empresas fornecedoras de serviços terceirizados, necessidades de gestores e fiscais de contratos e o interesse público, seu objetivo primaz. Na expectativa de alinhar tais interesses, buscou-se aplicar na gestão da conta vinculada dos contratos de terceirização da Universidade Federal de Goiás - UFG -, um modelo de avaliação de desempenho inspirado na Teoria do Stakeholder e no Performance Prism. A metodologia utilizada promoveu o confronto de perspectivas da UFG e dos seus stakeholders relacionados à gestão da conta vinculada. Os resultados, de forma geral, mostraram que a gestão da conta vinculada tem trazido benefícios tanto à UFG quanto aos seus stakeholders, principalmente no que se refere à maior segurança jurídica e redução nos ajuizamentos. Também mostraram a necessidade de ações que melhorem as capacidades disponibilizadas, especialmente o perfil de gestores e fiscais escolhidos e a estrutura dedicada à gestão e fiscalização dos contratos.
\end{abstract}

Palavras-chave: Conta vinculada. Contratos de terceirização. Teoria do Stakeholder. Performance Prism. Universidade Federal de Goiás.

\section{MANAGEMENT OF THE LINKED ACCOUNT, STAKEHOLDER THEORY AND PERFORMANCE PRISM APPLIED TO OUTSOURCING CONTRACTS: CASE STUDY AT THE GOIÁS FEDERAL UNIVERSITY}

\begin{abstract}
The compulsory nature of the linked account in the outsourcing contracts inserted the Federal Public Administration in an arena which several interests are presented: Rights of outsourced workers, companies that provide outsourced services, needs of managers and tax inspectors, and the public interest, their primary objective. In the expectation of aligning such interests, we sought to apply a performance evaluation framework, based on Stakeholder Theory and Performance Prism, to the management of the linked account of outsourcing contracts of the Goiás Federal University - UFG. The methodology used promoted the perspectives confrontation between UFG and its stakeholders both related to the liked account management. The results, in general, pointed out the linked account management has brought benefits both to the UFG and its stakeholders, mainly regarding to the greater legal certainty and appeals reduction. In addition, the benefits showed the need for actions that may improve the capacities available, especially the profile of managers and inspectors chosen, and the structure dedicated to the management and supervision of contracts.
\end{abstract}

Keywords: Linked account. Outsourcing contracts. Stakeholder theory. Performance prism. Goiás Federal University.

\footnotetext{
${ }^{1}$ Doutor em Engenharia da Produção pela Universidade Metodista de Piracicaba (Unimep). Professor da Universidade Federal de Goiás (UFG). eliseumachadojr@hotmail.com

${ }^{2}$ Mestre em Administração Pública pela Universidade Federal de Goiás (UFG). Servidor da Universidade Federal de Goiás (UFG). brunolobaolopes@hotmail.com
} 
Para se resguardar de eventuais processos trabalhistas decorrentes de contratos de terceirização, a Administração Pública Federal institucionalizou a possibilidade de assegurar reserva de valores suficientes para a quitação de determinadas obrigações trabalhistas, por meio da criação de uma conta bancária vinculada. Essa conta, instituída em caráter obrigatório com a promulgação da Instrução Normativa no 6 de 2013 da Secretaria de Logística e Tecnologia da Informação (SLTI), promoveria a garantia de tais obrigações mediante depósito mensal de suas provisões, retidas diretamente na nota fiscal do fornecedor.

A criação e a utilização da Conta Vinculada (CV) tem sido alvo de contestação por parte do Tribunal de Contas da União (TCU), que justifica sua posição sob duas alegações: a) por entender que tal exigência é excessiva e onerosa às empresas fornecedoras de mão de obra terceirizada, posto que se trata de interferência direta na gestão financeira destas; e, b) por perceber que a ineficiência da Administração Pública na fiscalização de seus contratos, somada à sobrecarga e despreparo dos fiscais, consolidaria a manutenção do entendimento por parte da Justiça do Trabalho quanto à responsabilização subsidiária da União pelo inadimplemento das obrigações trabalhistas (BRASIL, 2009).

A instituição da Conta Vinculada inseriu a Administração Pública Federal em uma arena na qual se apresentam diversos interesses, evidenciando a seguinte compreensão: ainda que sua atenção primeira seja o atendimento do interesse público, privilegiando o cidadão receptor do serviço, a administração pública não pode se omitir ante os efeitos diretos da terceirização a outros cidadãos envolvidos no processo, como: gestores, empresários, servidores e funcionários terceirizados.

Neste contexto, dimensões divergem ou se mostram de forma interdependente. De um lado as pessoas, partes interessadas, que serão tratadas à luz da Teoria do Stakeholder; de outro, os processos alinhados ao desempenho e, nesta direção, a utilização do Performance Prism. Estas duas dimensões serão combinadas por meio de um modelo de avaliação.

Tomou-se como objeto de estudo a UFG. Além da facilidade de obtenção de informações e proximidade dos autores com a instituição, esta também se depara com a necessidade de gerir a CV de forma que satisfaça os anseios dos Terceirizados, das Empresas de fornecimento de mão de obra terceirizada, dos Fiscais e Gestores de Contratos, dos Sindicatos, do Tribunal Superior do Trabalho (TST) e demais interessados, sem prejuízo do cumprimento da função pública.

Considerando o cenário apresentado e a relevância da teoria do Stakeholder como estratégia para solução de conflitos, o problema desta pesquisa pode ser apresentado pelo seguinte questionamento: Como a Universidade Federal de Goiás (UFG) pode se utilizar da Teoria do Stakeholder, combinada com a análise de desempenho Performance Prism, para obter um modelo de avaliação da gestão da conta vinculada?

Para responder ao problema de pesquisa, definiu-se como objetivo geral: propor na gestão da conta vinculada dos contratos de terceirização da UFG um modelo de avaliação de desempenho inspirado na teoria do Stakeholder e do Performance Prism, atento ao alcance dos diversos interesses inseridos na gestão da conta vinculada; E, como objetivos específicos: caracterizar os principais stakeholders relacionados à ges- 
tão da conta vinculada e aplicar um modelo de avaliação da conta vinculada na UFG inspirado no modelo de avaliação de desempenho Performance Prism e baseado na teoria do Stakeholder.

O presente trabalho justifica-se pela atualidade do tema, uma vez que a criação da conta vinculada é recente, sendo a obrigatoriedade de sua instituição para toda a esfera Pública Federal datada no final de 2013. Por fim, trata-se de matéria relevante, uma vez que a Administração Pública se mostra ineficiente na fiscalização de seus contratos.

\section{REFERENCIAL TEÓRICO}

\section{A Conta-Depósito Vinculada: origem e caracterização}

Dada a recorrência de condenações na justiça trabalhista, em 30 de abril de 2008 o Ministério do Planejamento, Orçamento e Gestão, por meio de sua Secretaria de Logística e Tecnologia da Informação (SLTI), publicou a Instrução Normativa - IN no 2 -, cujo objetivo era dispor sobre regras e diretrizes para a contratação de serviços continuados ou não. Para tanto, dedicou especial atenção, em seus artigos 31 a 35, à supervisão e fiscalização do cumprimento dos contratos, porém ganhou evidência depois de ser alterada pela IN no 3, de 15 de outubro de 2009, ao prever, nos editais de licitação da União, a seguinte possibilidade, ainda que facultativa: garantir reserva financeira para cobertura de determinadas obrigações trabalhistas nos contratos de serviços terceirizados, por meio da criação de uma conta bancária vinculada (BRASIL, 2014).

A IN no 2 de 2008, em caráter de melhoramento, ainda seria alterada mais duas vezes em 2009 (pela IN № 4, de 11 de novembro, e pela IN no 5, de 18 de dezembro de 2009). Somente com a IN no 6, de 23 de dezembro de 2013, entretanto, a conta vinculada, até então facultativa, tornou-se obrigatória para toda a Administração Pública Federal, sendo considerada parte integrante dos editais de licitação. Assim sendo, caberia ao ente ou órgão da Administração Pública prover a devida justificativa pela inviabilidade de sua utilização (BRASIL, 2014).

A Conta-Depósito Vinculada, bloqueada para Movimentação, é definida como uma maneira de pagamento diferida, na forma de depósito em conta bancária, cuja abertura deve ser realizada por órgão ou entidade da Administração Pública em decorrência de contratação de serviço de fornecimento de mão de obra terceirizada. Deve ser aberta em nome da empresa contratada, porém bloqueada para sua movimentação, e destinada unicamente para receber depósitos decorrentes de provisionamentos mensais de encargos trabalhistas, como consta no artigo 19-A e Anexo VII da IN no 2 . Objetiva-se, especificamente, a garantir o cumprimento de algumas obrigações trabaIhistas, sendo, a citada conta, sacada exclusivamente para o pagamento dessas obrigações. Cabe realçar que, somente depois de verificado o pagamento por parte da empresa contratada, a Administração Pública autoriza a movimentação junto a instituição financeira oficial para que seja liberado para a empresa o valor correspondente ao fato gerador (BRASIL, 2014, 2008). 
Os encargos trabalhistas que serão objeto de provisão pela adoção da conta vinculada são os seguintes: o 13ㅇ (décimo terceiro) salário, as férias e $1 / 3$ (um terço) constitucional, a multa sobre o FGTS e contribuição social sobre o aviso prévio e os encargos previdenciários incidentes sobre férias, $1 / 3$ constitucional de férias e 13으 salário (BRASIL, 2008).

Os provisionamentos serão realizados mediante desconto na fatura de serviços da empresa contratada e, em seguida, depósito em conta vinculada dos seguintes valores: a) $32,82 \%$ do total da remuneração dos funcionários vinculados ao contrato de terceirização, se o grau de risco de acidente de trabalho for leve; b) 33,03\% do total da remuneração dos funcionários vinculados ao contrato de terceirização, se o grau de risco de acidente de trabalho for médio; e, c) 33,25\% do total da remuneração dos funcionários vinculados ao contrato de terceirização, se o grau de risco de acidente de trabalho for grave (BRASIL, 2008).

Pelo disposto no artigo 19-A da Instrução Normativa no 2/2008, enquanto vigorar o contrato de terceirização, a empresa contratada poderá solicitar à Administração Pública a liberação de valores depositados na conta vinculada à medida que necessite realizar o pagamento de férias, 13 o salários e verbas rescisórias de seus funcionários, proporcionalmente ao tempo em que estiverem vinculados ao contrato assinado entre a administração Pública e a empresa contratada (BRASIL, 2008).

Essa liberação poderá ocorrer nas seguintes circunstâncias: a) parcial e anualmente - pela liberação dos valores provisionados do 13ㅇ de seus funcionários; b) parcialmente - pela liberação dos valores provisionados de férias e terço de férias (quando do gozo) e pela liberação das verbas rescisórias de seus funcionários (em virtude do desligamento dos mesmos); e, c) ao final do contrato - para pagamento das verbas rescisórias mencionadas, porém pelo motivo de término do contrato de terceirização firmado entre a administração pública e a empresa contratada (BRASIL, 2008).

\section{Teoria do Stakeholder: bases e aplicação na esfera pública}

A teoria do stakeholder, originada em meados dos anos 80 do século 20, surge como contraposição à visão essencialmente mercantilista das responsabilidades das empresas, entendendo-as como instituições sociais e, portanto, responsáveis pelas consequências geradas à sociedade pela sua atuação. Inova ao recomendar às empresas, quando da formulação de suas estratégias de mercado, maior atenção a todos os grupos e indivíduos afetados ou sujeitos a serem afetados na promoção dos objetivos da organização, denominados de stakeholders (FREEMAN, 1984; FREEMAN et al., 2010; FREEMAN; MC VEA, 2001).

Influenciada principalmente por estudos nas áreas de estratégia e planejamento empresarial corporativo, responsabilidade social das corporações, teoria de sistemas e teoria das organizações (FREEMAN et al., 2010; FREEMAN; MC VEA, 2001), a teoria do stakeholder apresenta-se como uma abordagem administrativa focada no gerenciamento ativo do ambiente corporativo, com fins de garantir a longevidade (MACHADO JR., 2009). 
Tendo suas bases em Freeman (1984), a teoria do stakeholder mostra que organizações devem dar maior atenção às necessidades dos grupos e indivíduos que possam influenciar ou serem influenciados por suas ações. Para isso, é necessário que tais grupos sejam identificados, classificados e suas relações gerenciadas. Assim, a organização tem à sua disposição ferramentas e conhecimentos capazes de equilibrar a satisfação das expectativas desses grupos e indivíduos, quando se depararem em situações de conflito de interesses entre eles.

Clarkson (1995) sugere uma primeira resposta ao questionamento principal da teoria do stakeholder (quem e o que verdadeiramente importa para garantir a sobrevivência da organização). Para tanto, admite-se a necessidade da identificação e satisfação de um grupo específico de stakeholders responsável pela continuidade da organização, denominando-os de stakeholders principais. Os demais stakeholders, chamados de secundários, ainda que não estejam no rol dos principais, de alguma forma influenciam ou são influenciados, afetam ou são afetados pelas operações da empresa.

Atkinson, Waterhouse e Wells (1997) defendem inclusive que a organização se concentre nas contribuições e interesses de seus stakeholders principais, e esses podem ser classificados em dois grupos: 1) os stakeholders do ambiente, assim considerados por definirem o ambiente externo da organização, influenciando-a ou condicionando-a em sua estratégia, relacionando-se principalmente com a organização na promoção de seus objetivos primários (exemplo: clientes, proprietários e comunidade), e 2) Os stakeholders de processo, assim classificados por se relacionarem com a organização de forma mais interna, em se tratando dos seus objetivos secundários, operacionais ou de processos (empregados e fornecedores).

Jones (1995), por sua vez, apresenta sua colaboração ao descrever a citada teoria como um framework capaz de integrar os interesses dos negócios e da sociedade. Em seus estudos atribui aos relacionamentos entre a organização e seus stakeholders semelhanças e propriedades equivalentes a um contrato e postula que relações de confiança e de cooperação ajudam a resolver problemas relacionados ao oportunismo, garantindo maior vantagem competitva e maior longevidade às organizações.

Ainda que a maioria dos artigos científicos que trataram da teoria do stakeholder tenha dirigido suas aplicações e estudos à realidade de empresas com fins lucrativos, essa tendência não se justificou por uma limitação teórica de aplicação e estudos na área pública, mas apenas por questão de preferência dos pesquisadores (HASNAS, 2013). Freeman (1984) argumenta que a teoria do stakeholder é aplicável em organizações diversas, independentemente de tamanho ou natureza.

Em ambientes públicos, em especial em Instituições de Ensino Superior Públicas, a sua aplicabilidade pode ser percebida em Machado Jr. (2009), ao desenvolver ferramenta de gestão baseando-se no princípio fundamental da Teoria do stakeholder (quem e o que realmente interessa à organização) que conduzirá a organização a uma maior longevidade. Em Gonçalves (2013), observa-se quanto à identificação dos stakeholders da Universidade de Lisboa, à luz do poder e do interesse destes na instituição, e a forma como influenciam a governança da instituição. Também se verifica em Mainardes et al. (2010), pela apresentação de um modelo que categorizou os stakeholders por importância, baseado unicamente na influência deste sobre a organização. Por fim, em Ferreira e Machado Jr. (2016), pela apresentação de um modelo de gestão estratégica e par- 
ticipativa baseado na Teoria do Stakeholder como instrumento facilitador para a gestão das Instituições de Ensino Superior, especialmente no atendimento das expectativas do Ministério da Educação (MEC).

Para Falco (2000), o fato de a Administração Pública estar inserida em um ambiente de múltiplos e diversos interesses, todos em condição de influenciar o processo decisório, exigindo desta a capacidade de reinterpretar-se constantemente, favorece a utilização da Teoria do stakeholder.

A Conta Vinculada insere a Administração Pública numa arena em que se apresentam diversos interesses (BRASIL, 2009). Neste sentido, a Administração Pública deve preocupar-se com os direitos do trabalhador, com os direitos das empresas contratadas para fornecimento de mão de obra terceirizada, com as necessidades de Gestores e Fiscais, e com o interesse público, objetivo primaz da Administração Pública (BRASIL, 2009).

\section{Avaliação de Desempenho Performance Prism}

As organizações, independentemente do setor em que atuam e do porte que possuem, almejam sempre melhorar seu desempenho. Para tanto, na mensuração de sua performance carecem de alternativas eficazes que forneçam informações suficientes e sirvam de base para tomadas de decisão e planejamentos (HOURNEAUX JUNIOR, 2010).

A utilização de ferramentas precisas de avaliação e a comunicação entre as partes interessadas, têm a capacidade de reduzir a distância entre o que o stakeholder deseja e o que a organização oferece (FALCO, 2000). Para Certo e Peter (2010), além de reduzirem essa distância, as ferramentas de Administração estratégica possibilitam a manutenção da saúde organizacional por meio da integração harmônica com seu ambiente.

Ante o exposto, optou-se pela ferramenta de Avaliação de Desempenho Performance Prism, uma vez que esta reúne especial preocupação com a relação entre as organizações e as pessoas, como parte significativamente interessada. Destaca-se também das demais ferramentas de análise de desempenho pelo fato de sua visão centrar-se em todos os stakeholders das organizações, sem prestigiar um grupo ou indivíduo específico (NEELY; KENNERLEY; ADAMS, 2007).

O modelo é de grande valia para a escolha dos indicadores adequados na avaliação de desempenho, compatível com as mais diversas formas de organizações, sejam elas sem fins lucrativos ou não. A intenção é explícitar questões críticas e incentivar os gestores a pensarem por meio da relação entre os vários indicadores, justamente porque outros modelos de avaliação de desempenho não o fazem de uma forma intuitiva (NEELY; ADAMS; CROWE, 2001).

Ante a citada exposição, percebe-se a fundamentação do modelo baseada em três princípios, quais sejam: a) atenção à totalidade dos stakeholders da organização; b) necessidade de as capacidades, os processos e as estratégias estarem ajustados e integrados para que se possa devolver valor aos vários stakeholders; e, c) necessidade de as organizações, bem como seus stakeholders, basearem sua relação nos fundamentos da parceria e da satisfação recíproca, ou seja, para que os stakeholders possam ter suas expectativas atendidas é necessário que também estejam dispostos a contribuir com o atendimento das expectativas da organização (MENDES, 2017). 
Em Mendes (2017) tem-se que esses três princípios fundamentais representam o alicerce do modelo de avaliação de desempenho Performance Prism, consolidando-o como uma das melhores e mais abrangentes ferramentas para detectar possibilidades de aperfeiçoamento da gestão.

O Performance Prism é representado por meio de um prisma triangular (cinco faces), conforme Figura 1, quando cada uma das faces se refere a uma perspectiva do processo de mensuração do desempenho, quais sejam: a) satisfação dos stakeholders: objetiva identificação dos stakeholders, seus desejos e necessidades; b) contribuição dos stakeholders: refere-se às exigências e interesses da organização junto aos seus stakeholders; c) estratégias: objetiva prover e aplicar na gestão estratégias ou ações que promovam os interesses tanto dos stakeholders quanto da organização; d) processos: identificação de processos ou procedimentos que devam ser executados para satisfazer às necessidades da organização e dos seus stakeholders; e, e) capacidades: objetiva investigar quais capacidades, habilidades e recursos são essenciais para os processos serem mais eficazes e eficientes (NEELY; ADAMS; CROWE, 2001).

Figura 1 - Modelo adaptado do Performance Prism

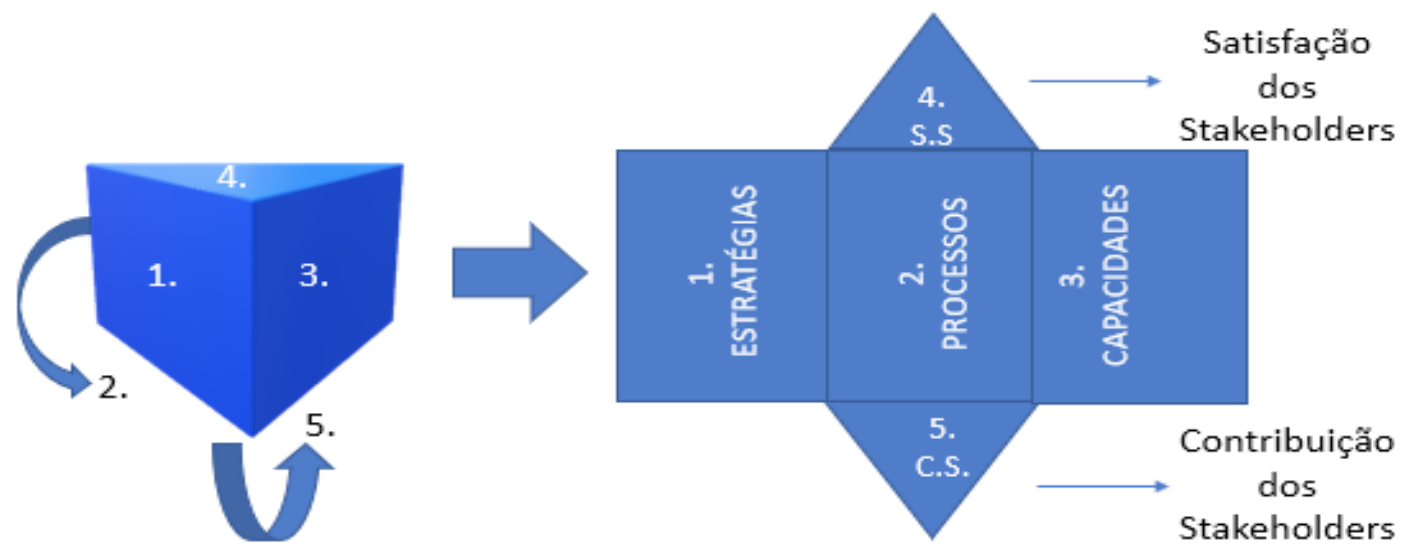

Fonte: Elaborada pelos autores com base em NEELY; ADAMS; CROWE (2001, p. 12).

Neely e Adams (2002), por sua vez, asseveram que o modelo Performance Prism reconhece como factual a existência de uma relação de sinergia entre a organização e todos os seus stakeholders (investidores, clientes, empregados, fornecedores, alianças ou comunidade local). Nesse modelo cada qual tem suas necessidades intrínsicas e as retribui também de forma singular. Essa característica do modelo Performance Prism, no sentido de entender a importância da relação recíproca entre organização e stakeholders, o faz único entre os modelos até então formulados.

\section{METODOLOGIA}

Esta pesquisa classifica-se como um estudo de caso. Em conformidade com Yin (2001, p. 32), o estudo de caso é apresentado como "uma investigação empírica que investiga um fenômeno contemporâneo dentro de seu contexto da vida real, especialmente quando os limites entre o fenômeno e o contexto não estão claramente definidos". De acordo com Mendonça, Rocha e Nunes (2008), o estudo de caso é caracterizado por ser uma pesquisa que tem como objeto de investigação uma entidade bem-definida. 
Nesses termos, o objeto de estudo escolhido foi a Universidade Federal de Goiás, e a abrangência do estudo compreendeu os contratos de terceirização, ainda em vigência, firmados no período de 2014 a 2016. Estes foram assim determinados pela proximidade dos pesquisadores com o objeto de estudo e pela exigência legal da instituição de a conta vinculada nos contratos de terceirização ser datada do final de 2013.

A pesquisa é exploratória, de natureza aplicada e, como proposta de intervenção, resultou em um modelo de avaliação de desempenho da gestão da conta vinculada.

Quanto à abordagem do problema, caracteriza-se como qualitativa, e em relação aos procedimentos metodológicos utilizados, optou-se pelo levantamento aqui entendido, conforme Prodanov e Freitas (2013, p. 57), como a "interrogação direta das pessoas cujo comportamento se quer conhecer".

O percurso metodológico foi composto de sete etapas: 1a) pesquisa bibliográfica e Documental; 2ㅇ) diagnóstico da gestão da conta vinculada da UFG; 3ํ) realização de entrevista com um gestor de contratos; 4ㅇ) classificação dos stakeholders; 5ㅇ) construção dos indicadores; 6ạ) elaboração e aplicação de questionário de avaliação da gestão da conta vinculada; e 7ạ) proposta de intervenção.

$\mathrm{Na} 1$ a etapa da pesquisa foram analisados artigos científicos e bibliografias qualificadas sobre os temas inerentes à pesquisa, que, somados às leis e regramentos, constituíram o arcabouço teórico basilar.

$\mathrm{Na} 2$ a etapa foi realizado diagnóstico da gestão da conta vinculada da UFG, quando se percebeu, no período de 2014 a 2016, a existência de 22 contratos vigentes de fornecimento de mão de obra terceirizada com 9 empresas distintas, englobando serviços de limpeza, condução de veículos, manutenção predial, manuseio de alimentos, vigilância, conservação de parques e jardins, etc. Estes fornecem à universidade a ocupação de 1.230 postos de trabalho, aproximadamente. Por parte da UFG, para a fiscalização, gestão dos contratos e da conta vinculada, existem 2 gestores e 10 fiscais administrativos.

$\mathrm{Na} 3$ a etapa foi realizada entrevista com um gestor de contrato, baseada no modelo de entrevista de Ribeiro (2014), cuja fundamentação teórica também se inspirou na teoria do stakeholder (FREEMAN, 1984) e no modelo de avaliação de desempenho Performance Prism (NEELY; ADAMS; CROWE, 2001).

$\mathrm{Na} 4$ a etapa foram classificados os stakeholders identificados durante a entrevista.

Na 5 a etapa, também com o auxílio das informações obtidas durante a entrevista, os indicadores foram caracterizados e organizados de forma que possibilitassem tanto a confeç̧ão de questionários específicos para cada grupo de stakeholders identificados quanto a avaliação dos cinco aspectos apresentados na teoria de Neely, Adams e Crowe (2001) do modelo de avaliação de desempenho Performance Prism, quais sejam: a) Satisfação dos Stakeholders; b) contribuição dos stakeholders; c) estratégias; d) processos; e, e) capacidades.

$\mathrm{Na}$ 6a etapa foi elaborado questionário de avaliação da gestão da conta vinculada inspirado na teoria do Stakeholder e no modelo de avaliação Performance Prism, visando a promover o confronto de perspectivas entre os diversos stakeholders relacionados à gestão da conta vinculada. O questionário foi aplicado junto aos stakeholders principais e seus resultados propiciaram a avaliação do grau de concordância dos entrevistados com cada questão, de acordo com uma escala Likert de cinco pontos.

Optou-se por definir o score da avaliação pelo número correspondente de cada alternativa, de forma que a pior avaliação ficasse com o score 1 e a melhor com score 5 , sendo 1 equivalente à alternativa Discorda muito, 2 Discordo um pouco, 3 Nem Concordo, Nem Discordo, 4 Concordo um pouco e 5 Concordo muito. 
A consolidação do resultado dos questionários indicou as avaliações de cada aspecto do prisma, de forma que aqueles indicadores da gestão da conta vinculada que tenham sido avaliados em médias aritméticas entre 1 e 3 (incluída a 3) sejam objeto de proposta de intervenção, enquanto os avaliados em médias aritméticas acima de 3 e menores que 4 carecem de atenção e monitoramento, e os avaliados entre 4 e 5 (incluída a 4) são satisfatórios.

Por último, na 7ạ etapa, diante dos resultados obtidos foi apresentada proposta de intervenção imediata para os quesitos que foram avaliados em médias aritméticas entre 1 e 3 (likert), com a indicação de ações de melhoramento dos indicadores.

Em síntese, a consecução das etapas metodológicas cumpre com os objetivos específicos e principal da pesquisa, pois apresentam a caracterização dos mais importantes stakeholders relacionados à gestão da conta vinculada, bem como resultam na obtenção e aplicação de um modelo de avaliação de desempenho inspirado na teoria do stakeholder e do Performance Prism.

\section{RESULTADOS DA ENTREVISTA}

$\mathrm{Na}$ entrevista em profundidade junto a um gestor designado para gerir os contratos de terceirização da UFG, obteve-se a identificação e a necessidade de satisfação de um determinado grupo de stakeholders, sem os quais a gestão da conta vinculada não seria possível, denominando-os de stakeholders principais ou primários. São eles: fiscais de contratos, funcionários terceirizados, gestores de contratos e fornecedores de serviços terceirizados. Os demais stakeholders (Sindicatos, Advocacia Geral da União - AGU, outros servidores, Tribunal de Contas da União - TCU, Bancos, Mídia e Tribunal Superior do Trabalho - TST), ainda que não estejam no rol dos principais, mas de alguma forma influenciam ou representam, e são influenciados ou afetados pelas operações dessa gestão, são denominados de stakeholders secundários, conforme ilustrado na Figura 2, elaborada com base em Clarkson (1995) e Freeman (1984).

Figura 2 - Classificação dos Stakeholders relacionados à gestão da conta vinculada

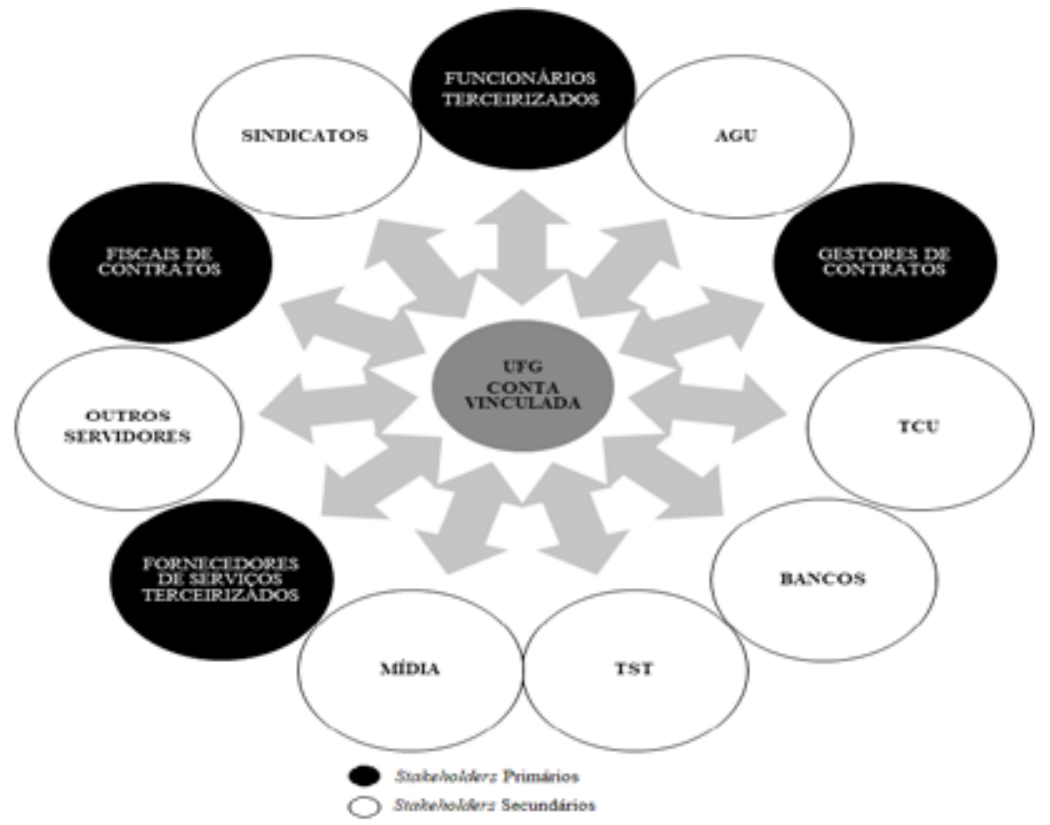

Fonte: Figura elaborada pelos autores com base em Freeman (1984) e Clarkson (1995). 
A entrevista com o gestor de contratos também possibilitou a obtenção de informações para a identificação dos indicadores para avaliação de desempenho da gestão da conta vinculada, organizados sob os aspectos apresentados na teoria de Neely, Adams e Crowe (2001), conforme segue:

\section{a) Aspecto Satisfação dos Stakeholders}

Em atenção ao aspecto satisfação dos stakeholders, buscou-se conhecer os stakeholders relacionados à gestão da conta, classificá-los quanto sua importância, entender suas necessidades junto a organização e obter os indicadores que poderiam mensurar sua satisfação. Dessa forma, foi possível construir o Quadro 1, identificando sete indicadores de satisfação, relacionando-os (ao assinalar com um X) com o(s) respectivo(s) stakeholder(s) que se deseja avaliar.

Quadro 1 - Identificação e organização dos indicadores de satisfação dos stakeholders

\begin{tabular}{|c|c|c|c|c|c|c|}
\hline № & SIGLA & INDICADOR & \multicolumn{4}{|c|}{ STAKEHOLDER } \\
\hline & SS & SATISFAÇÃO DOS STAKEHOLDERS & S1 & S2 & S3 & S4 \\
\hline 1 & SS-01 & Presença de conta vinculada nos contratos de terceirização & $\mathrm{X}$ & $\mathrm{x}$ & & \\
\hline 2 & SS-02 & Depósitos das retenções no prazo & $\mathrm{X}$ & $x$ & $\mathrm{X}$ & \\
\hline 3 & SS-03 & Pagamento do 13으 em dia & $\mathrm{X}$ & $x$ & & $\mathrm{x}$ \\
\hline 4 & SS-04 & Pagamento das férias em dia & $\mathrm{X}$ & $\mathrm{X}$ & & $\mathrm{x}$ \\
\hline 5 & SS-05 & Atendimento aos pedidos de saque no prazo legal & $\mathrm{X}$ & $\mathrm{X}$ & $x$ & \\
\hline 6 & SS-06 & Sensação de proteção dos direitos do trabalhador terceirizado & $x$ & $x$ & $x$ & $\mathrm{x}$ \\
\hline 7 & SS-07 & Recebimento correto da rescisão & & & & $\mathrm{x}$ \\
\hline \multicolumn{7}{|c|}{ Legendas: } \\
\hline \multicolumn{2}{|c|}{ S1 = Gestor de contratos } & \multicolumn{5}{|c|}{ S3 = Empresa fornecedora de mão de obra terceirizada } \\
\hline \multicolumn{3}{|c|}{ S2 = Fiscal administrativo de contratos } & & & & \\
\hline
\end{tabular}

Fonte: Elaborado pelos autores (2018).

b) Aspecto da Contribuição dos stakeholders

Quanto ao cumprimento do aspecto contribuição dos stakeholders, buscou-se conhecer o que a organização espera receber em troca da satisfação dos stakeholders, além de obter os indicadores capazes de mensurar essa contribuição. Dessa forma, foi possível construir o Quadro 2, identificando dois indicadores de contribuição, relacionando-os (ao assinalar com um X) com o(s) respectivo(s) stakeholder(s) que se almeja analisar.

Quadro 2 - Identificação e organização dos indicadores de contribuição dos stakeholders

\begin{tabular}{|c|c|c|c|c|c|c|c|}
\hline \multirow[t]{2}{*}{ № } & \multirow{2}{*}{$\frac{\text { SIGLA }}{\text { CS }}$} & \multirow{2}{*}{\multicolumn{2}{|c|}{$\begin{array}{c}\text { INDICADOR } \\
\text { CONTRIBUIÇÃO DOS STAKEHOLDERS }\end{array}$}} & \multicolumn{4}{|c|}{ STAKEHOLDER } \\
\hline & & & & S1 & S2 & S3 & S4 \\
\hline 8 & CS-01 & Sensaçã & maior segurança jurídica & $x$ & $x$ & $x$ & \\
\hline 9 & CS-02 & Percepçãc & redução nos ajuizamentos & $\mathrm{X}$ & $\mathrm{X}$ & $x$ & $x$ \\
\hline \multicolumn{8}{|c|}{ Legendas: } \\
\hline \multicolumn{3}{|c|}{ S1 = Gestor de contratos } & \multicolumn{5}{|c|}{ S3 = Empresa fornecedora de mão de obra terceirizada } \\
\hline \multicolumn{3}{|c|}{$\mathrm{S} 2$ = Fiscal administrativo de contratos } & S4 = Funcionário terceiriz & & & & \\
\hline
\end{tabular}

Fonte: Elaborado pelos autores (2018). 


\section{c) Aspecto das Estratégias desenvolvidas}

Para cumprimento do aspecto estratégias, buscou-se conhecer quais as estratégias ou ações a UFG põe em prática para satisfazer tanto as necessidades das pessoas e instituições, que são importantes para a gestão da conta vinculada, quanto para a satisfação própria, e como e quem estabelece as metas, objetivos e estratégias. Para este aspecto foram elencados 15 indicadores, relacionando-os (ao marcar com um X) com o(s) respectivo(s) stakeholder(s) que se deseja examinar, conforme o Quadro 3.

Quadro 3 - Identificação e organização dos indicadores de estratégias

\begin{tabular}{|c|c|c|c|c|c|c|}
\hline \multirow[t]{2}{*}{ № } & \multirow{2}{*}{$\begin{array}{c}\text { SIGLA } \\
\text { ES }\end{array}$} & \multirow{2}{*}{$\begin{array}{l}\text { INDICADOR } \\
\text { ESTRATÉGIAS }\end{array}$} & \multicolumn{4}{|c|}{ STAKEHOLDER } \\
\hline & & & S1 & S2 & S3 & S4 \\
\hline 10 & ES-01 & $\begin{array}{l}\text { Existência de controle individualizado das verbas devidas para cada } \\
\text { funcionário }\end{array}$ & $\mathrm{X}$ & $\mathrm{X}$ & $\mathrm{X}$ & \\
\hline 11 & ES-02 & Treinamento adequado para o exercício da função de gestor de contrato & $\mathrm{x}$ & $\mathrm{x}$ & & \\
\hline 12 & ES-03 & $\begin{array}{l}\text { Treinamento adequado para o exercício da função de fiscal admi- } \\
\text { nistrativo }\end{array}$ & $\mathrm{X}$ & $\mathrm{X}$ & & \\
\hline 13 & ES-04 & Necessidade de Setor específico para gestão da Conta Vinculada & $\mathrm{x}$ & $x$ & $x$ & \\
\hline 14 & ES-05 & $\begin{array}{l}\text { Conferência mensal dos valores retidos e da documentação para } \\
\text { fiscalização do contrato }\end{array}$ & $X$ & $\mathrm{X}$ & $\mathrm{X}$ & \\
\hline 15 & ES-06 & $\begin{array}{l}\text { Rapidez de comunicação entre empresa fornecedora de mão de } \\
\text { obra e UFG }\end{array}$ & $X$ & $\mathrm{X}$ & $\mathrm{X}$ & \\
\hline 16 & ES-07 & Facilidade de comunicação entre fornecedora de mão de obra e UFG & $x$ & $x$ & $\mathrm{x}$ & \\
\hline 17 & ES-08 & Continuidade de comunicação entre fornecedora de mão de obra e UFG & $x$ & $x$ & $x$ & \\
\hline 18 & ES-09 & Rapidez de comunicação entre funcionários terceirizados e UFG & $\mathrm{x}$ & $\mathrm{x}$ & & $\mathrm{x}$ \\
\hline 19 & ES-10 & Facilidade de comunicação entre funcionários terceirizados e UFG & $\mathrm{x}$ & $\mathrm{X}$ & & $\mathrm{x}$ \\
\hline 20 & ES-11 & Continuidade de comunicação entre funcionários terceirizados e UFG & $x$ & $x$ & & $x$ \\
\hline 21 & ES-12 & $\begin{array}{l}\text { Rapidez de comunicação entre gestores e fiscais administrativos de } \\
\text { contrato }\end{array}$ & $x$ & $\mathrm{x}$ & & \\
\hline 22 & ES-13 & $\begin{array}{l}\text { Facilidade de comunicação entre gestores e fiscais administrativos } \\
\text { de contrato }\end{array}$ & $x$ & $x$ & & \\
\hline 23 & ES-14 & $\begin{array}{l}\text { Continuidade de comunicação entre gestores e fiscais administrati- } \\
\text { vos de contrato }\end{array}$ & $x$ & $x$ & & \\
\hline 24 & ES-15 & $\begin{array}{l}\text { Adequação do manual da conta vinculada, disponibilizado pela } \\
\text { SLTI, à realidade da UFG }\end{array}$ & $x$ & $x$ & & \\
\hline \multicolumn{7}{|c|}{ Legendas: } \\
\hline \multicolumn{3}{|c|}{ S1 = Gestor de contratos } & $b r$ & $\mathrm{rc}$ & cana & \\
\hline \multicolumn{3}{|c|}{ S2 = Fiscal administrativo de contratos } & & & & \\
\hline
\end{tabular}

Fonte: Elaborado pelos autores (2018).

d) Aspecto dos Processos envolvidos na gestão da conta vinculada

Para composição do aspecto processos, buscou-se identificar e compreender quais processos e procedimentos a UFG dispõe na gestão da conta vinculada para satisfazer tanto suas necessidades quanto as necessidades de seus stakeholders. Com base nestas informações foi possível identificar os quatro indicadores que compõem o aspecto processos, relacionando-os (ao marcar com um X) com o(s) respectivo(s) stakehol$\operatorname{der}(s)$ que se deseja examinar, conforme o Quadro 4. 
Quadro 4 - Identificação e organização dos indicadores de processos

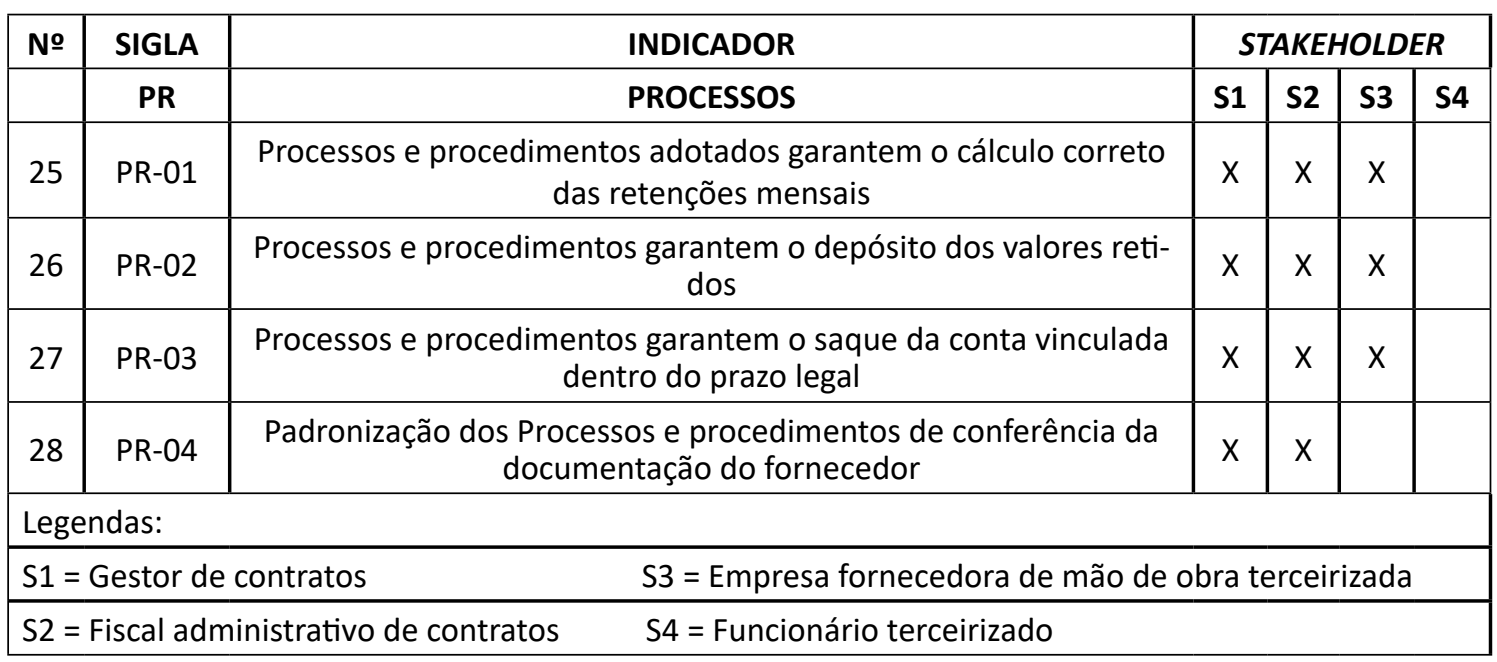

Fonte: Elaborado pelos autores (2018).

\section{e) Aspecto Capacidades}

Na composição do aspecto capacidades, buscou-se identificar que capacidades, recursos e habilidades a UFG necessita para fazer os processos funcionarem de modo mais eficaz e eficientemente, e se existem controles que garantam que estas habilidades estão sendo desenvolvidas e incorporadas. Foram obtidos dez indicadores para este aspecto, listados e relacionados aos stakeholders que avaliam, conforme o Quadro 5.

Quadro 5 - Identificação e organização dos indicadores de capacidades

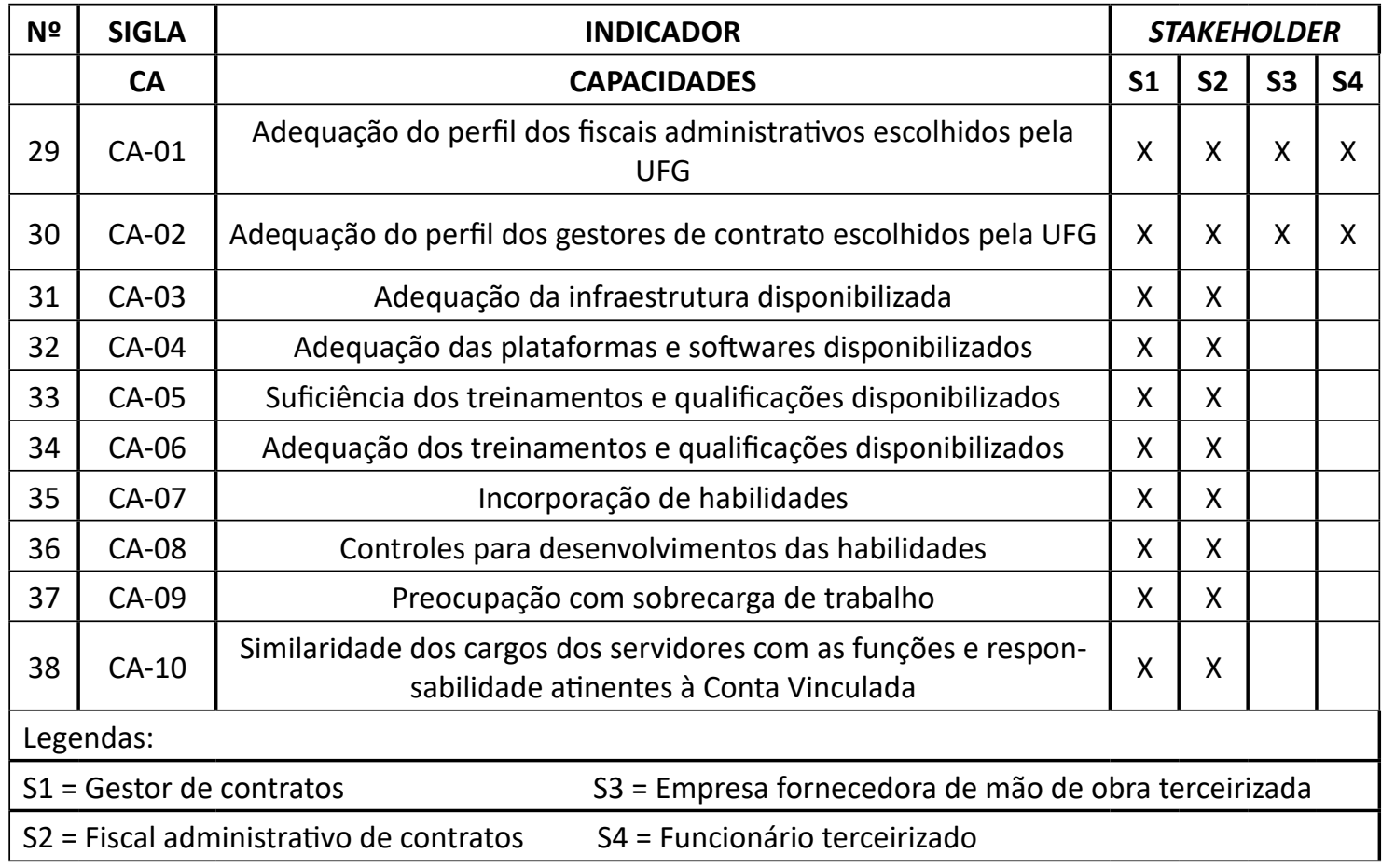

Fonte: Elaborado pelos autores (2018). 


\section{Resultados dos Questionários}

Os questionários foram aplicados entre os dias 23/10/2017 e 23/11/2017, sendo encaminhados via e-mail para todos os gestores, fiscais administrativos e empresas fornecedoras de mão de obra terceirizada, obtendo-se respostas de dois gestores, cinco fiscais administrativos e seis empresas.

Quanto aos funcionários terceirizados, os questionários foram aplicados por meio de abordagem direta a 39 destes.

a) Resultado do questionário aplicado em fiscais administrativos e gestores

Ao comparar-se as avaliações realizadas entre gestores e fiscais administrativos, foram identificados os pontos de concordância e discordância quanto aos indicadores que necessitam de intervenção. Por exemplo, a concordância de fiscais e gestores quanto à necessidade de intervenção imediata no indicador ES - 02 (treinamento adequado para o exercício da função de gestor de contrato), cujas avaliações de ambos os stakeholders apresentaram médias entre 1 e 3, enquanto as avaliações de fiscais e gestores a respeito do indicador SS-02 (depósitos das retenções no prazo), representaram discordância quanto à necessidade de intervenção imediata, posto que os fiscais avaliaram tal indicador em média fora da necessidade de intervenção (score acima de 3 ), enquanto os gestores avaliaram com média indicativa de intervenção (scores entre 1 e 3), como mostra o Gráfico 1.

Gráfico 1 - Avaliação da gestão da conta vinculada na perspectiva dos gestores versus fiscais administrativos

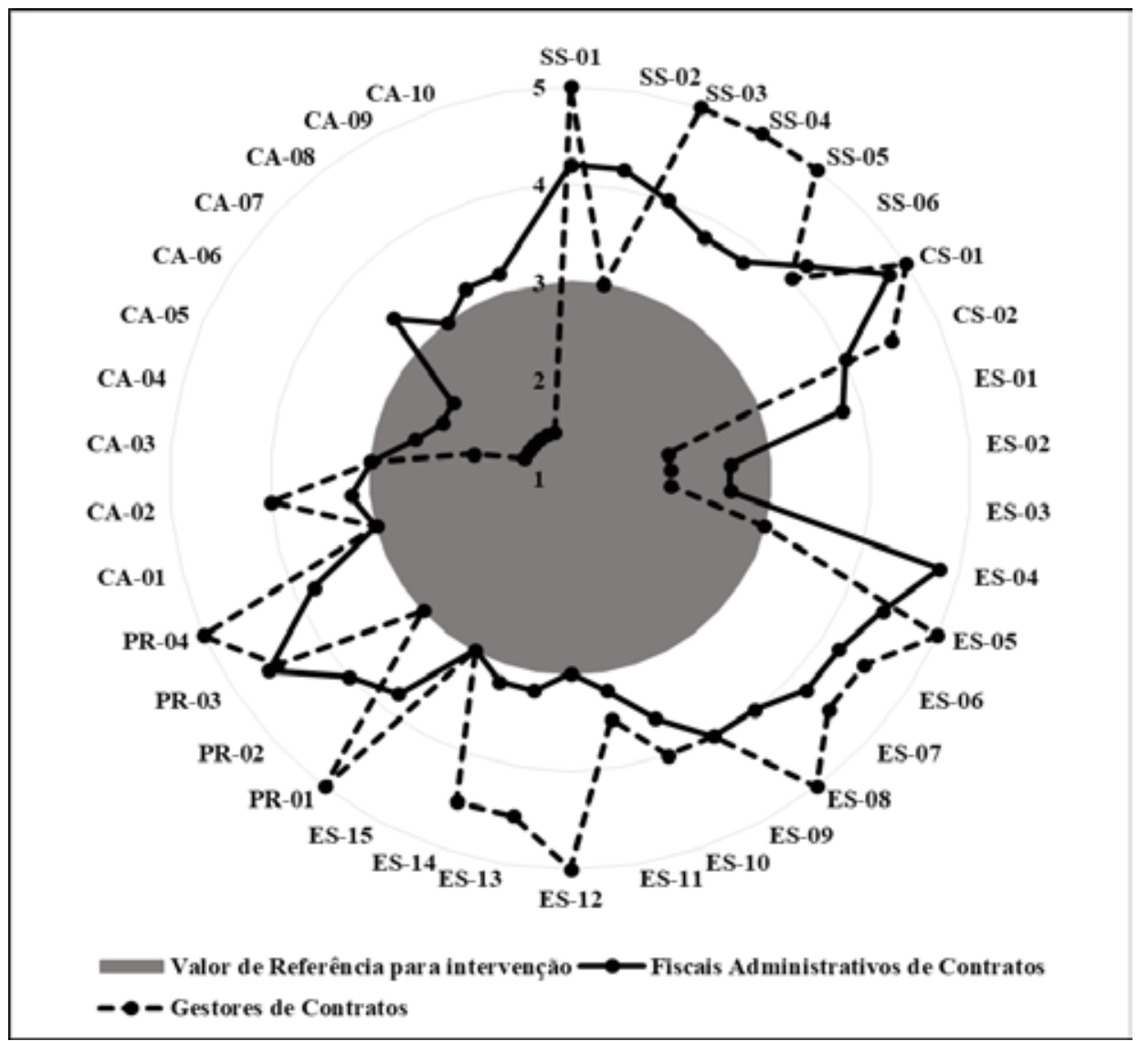

Fonte: Elaborado pelos autores (2018). 
Entre os aspectos da gestão da conta vinculada avaliados por gestores e fiscais administrativos, constatou-se que ambos apontaram a necessidade de intervenção, isto é, avaliaram com médias entre 1 e 3 , incluindo 3 os seguintes indicadores:

1) Aspecto estratégias: ES-02 (treinamento adequado para o exercício da função de gestor de contrato), ES-03 (treinamento adequado para o exercício da função de fiscal administrativo de contrato) e ES-15 (adequação do manual da conta vinculada, disponibilizado pela SLTI à realidade da UFG);

2) Aspecto capacidades: CA-01 (adequação do perfil dos fiscais administrativos escolhidos pela UFG), CA-03 (adequação da infraestrutura disponibilizada), CA-04 (adequação das plataformas e softwares disponibilizados), CA-05 (suficiência dos treinamentos e qualificações disponibilizados), CA-06 (adequação dos treinamentos e qualificações disponibilizados) e CA-08 (Controles para desenvolvimentos das habilidades).

Os principais conflitos de avaliação apurados entre gestores e fiscais remetem aos seguintes indicadores: SS-02 (depósitos das retenções no prazo) avaliado pelos gestores com média 3 e pelos fiscais com média 4,20; ES-04 (necessidade de setor específico para gestão da conta vinculada) avaliado pelos gestores com média 3 e pelos fiscais com média 4,80; ES-12 (rapidez de comunicação entre gestores e fiscais administrativos de contrato) avaliado pelos gestores com média 5 e pelos fiscais com média 3, e PR-02 (processos e procedimentos garantem o depósito dos valores retidos) avaliado pelos gestores com média 3 e pelos fiscais com média 4.

b) Resultado do questionário aplicado com empresas fornecedoras de mão de obra terceirizada comparado com o resultado de fiscais e gestores

Para obtenção do Gráfico 2, relacionou-se o resultado obtido dos indicadores comuns à avaliação das empresas de fornecimento de mão de obra terceirizada com as avaliações dos gestores e fiscais administrativos de contrato, como segue.

Gráfico 2 - Avaliação comparada de fiscais administrativos, gestores e empresas quanto à gestão da conta vinculada

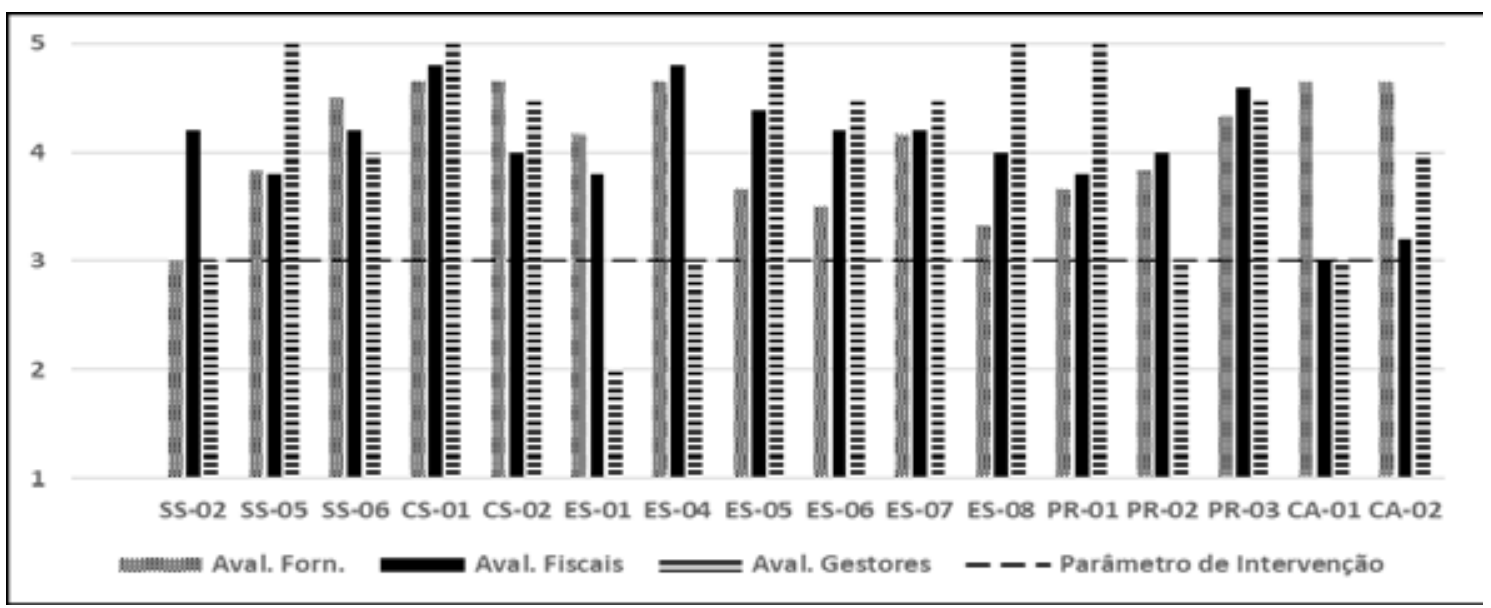

Fonte: Elaborado pelos autores (2018).

Quanto aos indicadores passíveis de avaliação tanto por fornecedores de mão de obra terceirizada quanto por gestores e fiscais administrativos, cabe expor o seguinte: ainda, porém, que os resultados não tenham indicado unanimidade de intervenção para 
um indicador específico, pela avaliação insatisfatória de pelo menos dois dos stakeholders, serão objetos de intervenção os indicadores: SS-02 (depósito das retenções no prazo) avaliados por fornecedores de mão de obra terceirizada, ficais e gestores com médias de 3, 4,20 e 3, respectivamente, e CA-01 (adequação do perfil dos fiscais administrativos escolhidos pela UFG) avaliados por fornecedores de mão de obra terceirizada, fiscais e gestores com médias de 4,67, 3 e 3, respectivamente.

c) Resultado do questionário aplicado com funcionários terceirizados comparado com o resultado de gestores e fiscais

Constatou-se que na percepção dos funcionários terceirizados não houve nenhum indicador cuja avaliação represente motivação de uma abordagem imediata.

Relacionou-se o resultado obtido dos indicadores comuns à avaliação dos funcionários terceirizados com as avaliações dos gestores e fiscais administrativos de contrato, e obteve-se o Gráfico 3.

Gráfico 3 - Avaliação comparada de fiscais administrativos, gestores e funcionários terceirizados quanto à gestão da conta vinculada

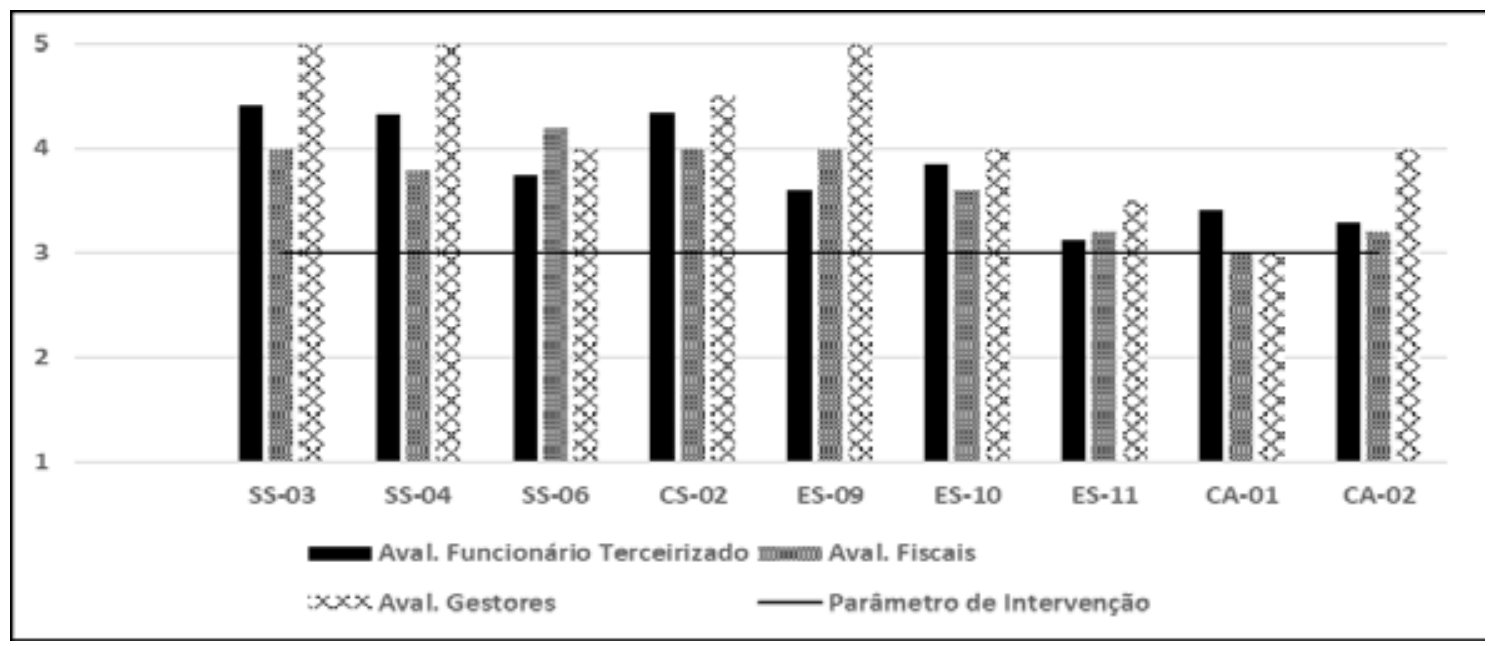

Fonte: Elaborado pelos autores (2018).

Faz-se oportuno esclarecer que, quando analisadas em conjunto, as avaliações realizadas por funcionários terceirizados, gestores e fiscais administrativos apresentaram, para alguns indicadores, resultados comuns muito próximos do indicativo de intervenção (média 3), como: ES-11(continuidade de comunicação entre funcionários terceirizados e UFG), CA-01 (adequação do perfil dos fiscais administrativos escolhidos pela UFG), CA-02 (adequação do perfil dos gestores de contrato escolhidos pela UFG).

\section{PROPOSTA DE INTERVENÇÃO IMEDIATA}

Diante dos resultados obtidos com o modelo de avaliação da gestão da conta vinculada, produziu-se instrumento de intervenção com ações de correção imediata dos indicadores avaliados em médias 1 (um) a 3 (três), de forma que os indicadores comuns aos stakeholders estão identificados com um X, e acrescidos de $\mathrm{O}$ caso o stakeholder NÃO o tenha avaliado dentro da faixa de intervenção, e, quando não existir qualquer sinalização, seja ela X ou XO, significa que o indicador não foi objeto de avaliação pelo 
referido stakeholder. Exemplo: O indicador SS-02 apresenta X para os stakeholders S1 (gestor de contratos), S2 (fiscal administrativo de contratos) e S3 (empresa fornecedora de mão de obra terceirizada), sinalizando que o indicador foi objeto de avaliação pelos referidos stakeholders. No stakeholder S3 (empresa fornecedora de mão de obra terceirizada), porém, percebe-se o $X$ acompanhado de $O$, o que significa que este foi o único que avaliou o indicador fora da faixa de intervenção, NÃO carecendo de medidas corretivas. Em suplemento, percebe-se a ausência de qualquer sinalização, seja ela X ou XO, para o stakeholder S4 - (funcionários terceirizados), significando que o indicador SS-02 não foi objeto de avaliação pelo referido stakeholder, conforme Quadro 6.

Quadro 6 - Proposta de intervenção imediata

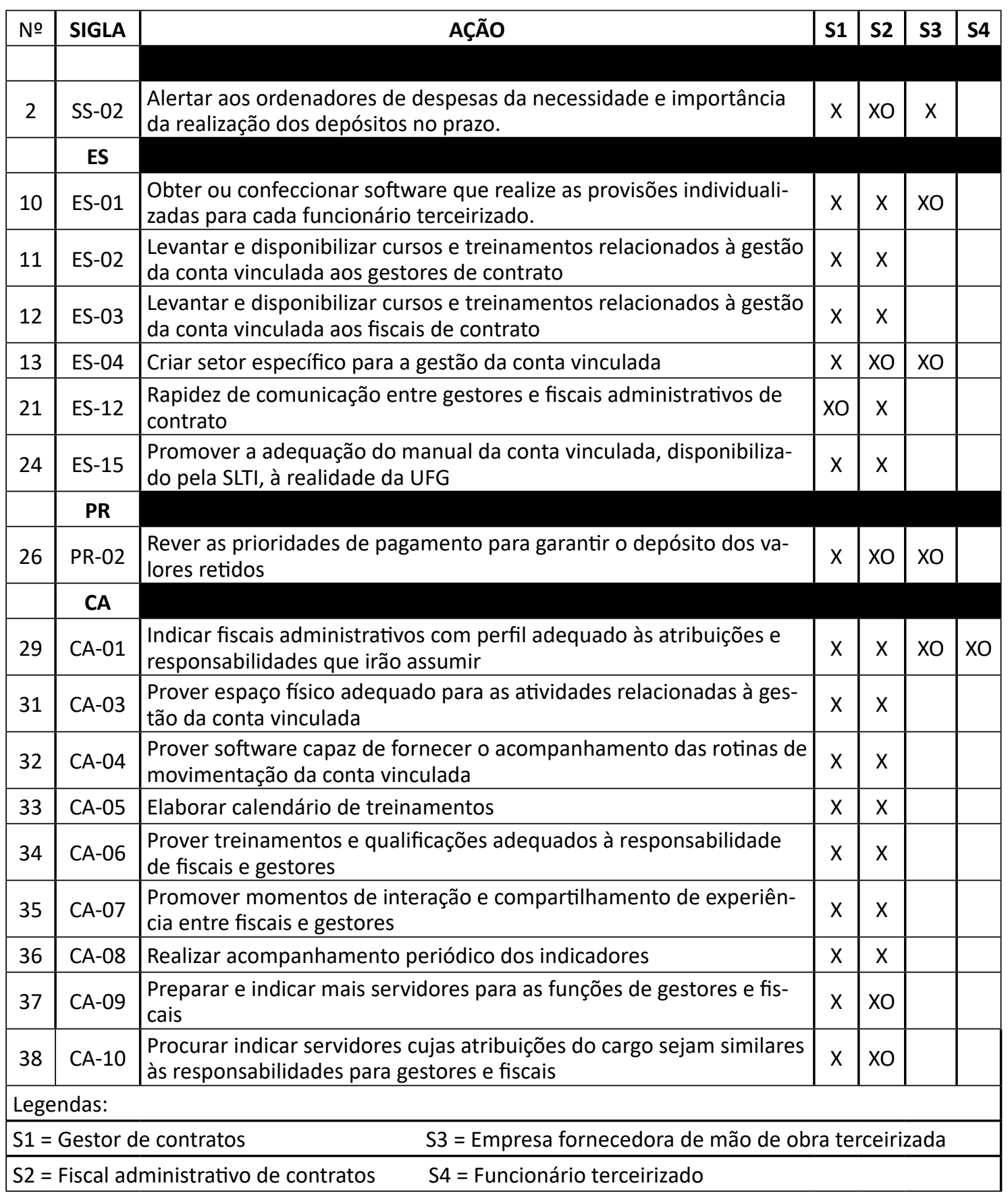

Fonte: Elaborado pelos autores (2018). 


\section{CONSIDERAÇÕES FINAIS}

Propôs-se, com este trabalho, um olhar mais amplo, que não privilegie atenção apenas a um dos partícipes do processo de terceirização, mas que entenda a complexidade do processo, na percepção de que uma gestão bem-avaliada deva ocupar-se de todas as relações dela decorrentes, demandando atenção a todos os interesses nela inseridos, numa rede harmoniosa de relacionamentos.

A expectativa desta pesquisa era facilitar o entendimento entre os diversos stakeholders inseridos na problemática da gestão da conta vinculada, utilizando-se de estratégias de integração e sugerindo um modelo de avaliação que promovesse a convergência dos diversos interesses no propósito do bem comum.

Desta expectativa surgiu o problema de pesquisa: Como a UFG pode se utilizar da Teoria do Stakeholder, combinada com a análise de desempenho Performance Prism, para obter um modelo de avaliação da gestão da conta vinculada?

Com base na teoria do Stakeholder, especialmente nas contribuições de Freeman (1984) e Clarkson (1995), somadas ao resultado do questionário adaptado de Ribeiro (2014), aplicado junto ao gestor de contratos, foi possível cumprir com o objetivo específico de caracterizar os principais stakeholders relacionados à gestão da conta vinculada. Tais contribuições e resultados, reforçados com os estudos de Neely, Adams e Crowe (2001) sobre o Performance Prism, possibilitaram o cumprimento do outro objetivo específico e, consequentemente, do objetivo geral, quais sejam: aplicar e propor um modelo de avaliação da conta vinculada na UFG inspirado no Performance Prism e na Teoria do Stakeholder, atento ao alcance dos diversos interesses inseridos na gestão desta conta.

Com a proposição e aplicação do modelo, foram captadas as percepções dos stakeholders quanto à gestão da conta vinculada, e, dentre os resultados obtidos, destacam-se os seguintes:

a) quanto ao aspecto contribuições dos stakeholders, as percepções destes mostraram que o resultado da gestão da conta vinculada tem trazido benefícios de sensação de maior segurança jurídica e percepção de redução nos ajuizamentos;

b) quanto ao aspecto capacidades, obteve-se avaliação baixa para a maioria dos indicadores, principalmente nas percepções de fiscais e gestores de contratos, exprimindo a necessidade de melhorar o perfil dos fiscais administrativos escolhidos, melhorar a estrutura dedicada à gestão e fiscalização dos contratos, ter melhores plataformas e softwares, a necessidade de mais e melhores treinamentos, e a preocupação com o controle e com o desenvolvimento das habilidades necessárias para a execução das funções de fiscais administrativos e gestores de contrato;

c) quanto ao aspecto satisfação dos stakeholders, obteve-se avaliações que indicam que a realização dos depósitos das retenções não tem ocorrido no prazo legal sob a percepção tanto dos gestores, quanto dos fornecedores. O resultado disto poderá ser a indisponibilidade do valor na conta vinculada quando da necessidade de saque para a quitação das verbas trabalhistas a que se destina a tal conta, acarretando em interferência direta na saúde financeira do fornecedor, que tinha como certa a presença destes valores para quitação de suas obrigações junto aos seus funcionários, a possibilidade de cobrança de juros à UFG por atraso no depósito e, por fim, a insatisfa- 
ção dos trabalhadores terceirizados pelo não recebimento ou recebimento em atraso de seus direitos, contribuindo, sobremaneira, para a responsabilização subsidiária da união para com tais direitos;

d) quanto ao aspecto processos, o único indicador que obteve avaliação baixa diz respeito à percepção dos stakeholders quanto aos processos e procedimentos necessários para que os valores retidos sejam depositados em conta vinculada no momento em que também é quitada a Nota Fiscal. Isso reafirma o que foi dito anteriormente quanto à não realização do depósito no prazo; e,

e) quanto ao aspecto estratégias, obteve-se avaliações que indicaram a inexistência de controle individualizado dos direitos dos trabalhadores terceirizados; a necessidade de cursos e treinamentos adequados para cada servidor, seja ele gestor ou fiscal; e a urgência de um manual próprio de operacionalização da conta vinculada, adequado à realidade da UFG.

Por fim, foi elaborado um plano de ação para correção e melhoramento dos indicadores que necessitam de intervenção imediata, ou seja, que tenham sido avaliados pelos stakeholders em média de scores dentro do intervalo de 1 a 3 , incluindo o 3 .

A respeito das limitações deste trabalho, destaca-se que, diante da velocidade de alterações das normatizações que tratam da conta vinculada, foi possível perceber que alguns fiscais não se sentiram à vontade para responder a pesquisa, inclusive desconhecendo atribuições que legalmente seriam suas. Afinal, somente em 2017, com a publicação da IN no 05, é que houve uma definição clara das responsabilidades e atribuições de fiscais e gestores.

Além de todas as contribuições já mencionadas no início das considerações deste trabalho, entende-se que os procedimentos metodológicos e/ou até mesmo o modelo proposto, possam ser replicados em outras instituições.

Sugere-se, para novas pesquisas, a realização de análises de correlação entre os indicadores elencados nesta investigação, bem como a realização de estudos que testem a correlação entre redução de ajuizamentos decorrentes de demandas de funcionários terceirizados e a instituição da conta vinculada.

\section{REFERÊNCIAS}

ATKINSON, A.; WATERHOUSE, J.; WELLS, R. A Stakeholder Approach to Strategic Performance Measurement. Sloan Management Review, v. 38, n. 3, p. 25-37, 1997.

BRASIL. Ministério do Planejamento, Orçamento e Gestão. Secretaria de Logística e Tecnologia da Informação. Instrução Normativa no 2, de 30 de abril 2008. Dispõe sobre regras e diretrizes para a contratação de serviços, continuados ou não. Disponível em: http://www.comprasgovernamentais.gov.br. Acesso em: 2 jun. 2016.

BRASIL. Tribunal de Contas da União. Acórdão TCU № 4720/2009 de 8 setembro de 2009. Brasília, 2009. Disponível em: https://contas.tcu.gov.br. Acesso em: 2 jun. 2016.

BRASIL. Cartilha sobre conta vinculada. Ministério do Planejamento, Orçamento e Secretaria de Logística e Tecnologia da Informação, novembro 2014. Disponível em: http://www.comprasgovernamentais.gov. br/arquivos/terceirizacao/cartilha-conta-vinculada.pdf. Acesso em: 27 maio 2016.

CERTO, S. C.; PETER, J. P. Administração estratégica: planejamento e implantação das estratégias. São Paulo: Pearson Education do Brasil, 2010.

CLARKSON, M. B. E. A stakeholder framework for analysing and evaluating corporate social performance. Academy of Management Review, v. 20, n. 1, p. 92-117, 1995.

FALCO, S. E. D. Instrumentos de voice giving na relação entre os cidadãos e a administração pública: a carta dos serviços. Revista do Serviço Público, v. 51, n. 3, p. 5-27, jul./set. 2000. 
FERREIRA, K. B.; MACHADO JR., E. V. Modelo de gestão estratégica e participativa para instituições de Ensino Superior: estudo de caso do Instituto Federal de Goiás. COLÓQUIO INTERNACIONAL DE GESTIÓN UNIVERSITARIA - CIGU, 16., 2016. Arequipa, nov. 2016.

FREEMAN, R. E. Strategic management: A stakeholder perspective. Boston: Pitman, 1984.

FREEMAN, R. E. et al. Stakeholder theory: the state of the art. Cambridge, UK: Cambridge University Press, 2010.

FREEMAN, R. E.; MC VEA, J. A Stakeholder Approach to Strategic Management. Darden Graduate School of Business Administration, University of Virginia, Working Paper № 1-2; Social Science Research Network Electronic Paper. 2001. p. 32.Available from: http://papers.ssrn.com/paper.taf?abstract_id=263511 a 06/06/17.

GONÇALVES, R. P. R. E. Análise de stakeholders de uma instituição de Ensino Superior, o caso do ISEG (Universidade de Lisboa). 2013. Dissertação (Mestrado em Gestão e Estratégia Industrial) - Universidade de Lisboa, Lisboa, 2013. p. 44.

HASNAS, J. Whither Stakeholder Theory? A Guide for the Perplexed Revisited. J Bus Ethics, Washington, EUA, v. 112, n. 1, p. 47-57, jan. 2013.

HOURNEAUX JUNIOR, F. Relações entre as partes interessadas (stakeholders) e os sistemas de mensuração do desempenho organizacional. 2010. Tese (Doutorado em Administração) - Universidade de São Paulo, Faculdade de Economia, Administração e Contabilidade, São Paulo, 2010.

JONES, T. Instrumental stakeholder theory: A synthesis of ethics and economics. Academy of Management Review, v. 20, n. 2, p. 404-437, 1995.

MACHADO JR., V. Sinergia dos Stakeholders: um framework de gestão e responsabilidade social - estudo de caso em instituição de Ensino Superior brasileira. 2009, 312f. Tese (Doutorado) - Universidade Metodista de Piracicaba, Santa Bárbara D’Oeste, 2009.

MAINARDES, W. et al. Categorização por importância dos Stakeholders das Universidades. Revista Ibero Americana de Estratégia - RIAE, São Paulo, v. 9, n. 3, p. 4-43, set./dez. 2010. ISSN 2176-0756.

MENDES, L. A. L. Performance Prism: um modelo para gerenciar o sucesso dos negócios. Disponível em: http: //www.fdc.org.br/hotsites/mail/PERFORMANCEPRISMPM.pdf, 2017. Acesso em: 15 fev. 2017.

MENDONÇA, A. F. D.; ROCHA, C. R. R.; NUNES, H. P. Trabalhos acadêmicos: planejamento, execução e avaliação. Goiânia: Faculdades Alves Faria, 2008.

NEELY, A.; ADAMS, C. Managing with measures: The stakeholder Perspective. Control, p. 29-31, set. 2002. NEELY, A.; ADAMS, C.; CROWE, P. The performance prism in practice. Measuring Business Excellence, v. 5, n. 2, p. 6-13, 2001.

NEELY, A.; KENNERLEY, M.; ADAMS, C. Performance measurement frameworks: a review. In: NEELY, A. Business performance measurement: Unifying theory and integrating practice. Cambridge: Cambridge University Press, 2007.

PRODANOV, Cleber Cristiano; FREITAS, Ernani Cesar de. Metodologia do trabalho científico: métodos e técnicas da pesquisa e do trabalho acadêmico. 2. ed. Novo Hamburgo: Feevale, 2013. Disponível em: http://www.feevale.br/editora. Acesso em: 30 jul. 2017.

RIBEIRO, Hewdy Lobo. Gestão estratégica de desempenho na perspectiva dos stakeholders: um estudo de caso no Hospital Lacan. 2014. Dissertação (Mestrado em Administração) - Unip, São Paulo, 2014.

YIN, R.K. Estudo de caso: planejamento e métodos. Porto Alegre: Bookman, 2001. 